\title{
An in situ hot stage transmission electron microscopy study of the decomposition of Fe-C austenites
}

\author{
M. ONINK, F. D. TICHELAAR, C. M. BRAKMAN, E. J. MITTEMEIJER, \\ S. VAN DER ZWAAG \\ Laboratory for Materials Science, Delft University of Technology, Rotterdamseweg 137, \\ 2628 AL Delft, The Netherlands
}

\begin{abstract}
Hot stage transmission electron microscopy is applied to determine the growth mechanism during decomposition of austenite in hypo-eutectoid $\mathrm{Fe}-\mathrm{C}$ austenites. The austenite-ferrite interface is mostly curved and moves sluggishly with periods of acceleration and deceleration. In some cases the interface is nearly straight and effectively immobile. Then, migration takes place by means of ledges which displace parallel to the immobile straight interface. The ledges migrate at a rate equal to the migration rate predicted for diffusion controlled migration. The highest migration rates observed for the curved interface are nearly equal to that calculated for diffusion controlled growth. The observed succession of periods of acceleration and deceleration for the curved interface is not predicted in the common theories for interface mobility during phase transformation. Detailed examination of region around the interface indicate that stress build up and stress relaxation are responsible for the deceleration and acceleration respectively. The stresses are due to the volume misfit between the ferrite formed and the parent austenite.
\end{abstract}

\section{Introduction}

In this work, hot stage transmission electron microscopy was used for an in-situ study of the austenite decomposition in high-purity hypo-eutectoid iron-carbon alloys at temperatures in the austenite-ferrite two-phase region of the $\mathrm{Fe}-\mathrm{C}$ phase diagram. The transformation involves a change in crystal strcture of the iron lattice as well as a redistribution of the carbon, interstitially dissolved provided the solubility of carbon in ferrite (maximum of $0.02 \mathrm{wt} \% \mathrm{C}$ at $1000 \mathrm{~K}$ ) is lower than the initial carbon concentration in the austenite, which is true in most cases. In view of the necessary redistribution of carbon, the kinetics of the ferrite formation is often modelled using carbon diffusion in austenite as the rate determining step [1-4]. The transformation interface is then interpreted as a semipermeable membrane for the carbon atoms which moves in the direction of the remaining austenite with a rate supposed to be such that the carbon concentration at the interface maintains the equilibrium value. The concept of a diffusion controlled movement of the interface leads to a continuous migration rate of the interface which eventually decreases due to the overlap of diffusion fields of surrounding ferrite grains. In the diffusion based models the material is regarded as an isotropic continuum with respect to its intrinsic properties and the influence of the local microstructure on the transformation behaviour is neglected. However, grain boundaries and precipitates are known to affect the transformation behaviour. Also the presence of local stresses due to a change in volume upon the phase transformation, that are a strong function of the carbon concentration in austenite at the interface $[5,6]$, may affect the velocity of the interface. When the effects of the local microstructure become significant or even rate determining for the migration rate of the transformation interface, the transformation proceeds under mixed (both interface and diffusion) or pure interface control, respectively, as opposed to pure diffusion control as described above.

To investigate the effects of local microstructures on the interface mobility, in-situ examination of moving boundaries using microscopic techniques is necessary. In-situ microscopic techniques at all ranges of magnification have been used in the study of various types of phase transformations. The range extends from relatively low magnifications as used in visible light microscopy [7] to high magnifications used in transmission electron microscopy (TEM) [8-14] and thermionic electron emission microscopy (THEEM) [18] and very high magnification up to the atomic resolution used in scanning tunnelling microscopy $[15,16]$. The suitability of hot stage TEM for the study of high temperature solid-state phese transformations has been demonstrated for phase transformations in quartzite [8], $\mathrm{Al}-\mathrm{Ag}$ alloys [9], $\mathrm{Al}-\mathrm{Cu}-\mathrm{Mg}-\mathrm{Ag}$ alloys [10] and steels [11-14]. It has been shown that the interface mobility of transformation interfaces in $\mathrm{Fe}-\mathrm{C}-\mathrm{Mo}$ alloys is largely influenced by the interface 
structure $[13,14]$, i.e. a distinction was made between fast moving "incoherent" interfaces and slowly moving "structured" interfaces. It has been claimed that these results also apply to $\mathrm{Fe}-0.4 \mathrm{wt} \% \mathrm{C}$ alloys. In the literature, data on migration rates are obtained ex-situ from analysing partially transformed $\mathrm{Fe}-\mathrm{C}$ specimens [17]. In the present work, hot stage TEM is applied to an $\mathrm{Fe}-0.36 \mathrm{wt} \% \mathrm{C}$ alloy and an $\mathrm{Fe}-0.71 \mathrm{wt} \%$ $\mathrm{C}$ alloy. The migration rates of the transformation interface were determined directly but at higher magnifications than in the thermionic electron emission microscopy study. This allowed a more detailed analysis of phenomena near the interface. The experimental data are compared to values predicted for the interface mobility in the case of diffusion controlled migration and in the case of interface controlled migration. Deviations of the experimental values from the theoretically predicted values are discussed in terms of the effect of local stress and microstructure on the interface mobility.

\section{Specimen preparation}

The alloys were prepared by arc melting iron under an argon flow while adding pure graphite to obtain the carbon concentration required. Austenitizing took place at $1273 \mathrm{~K}$ for $15 \mathrm{~min}$, after which the solid alloy was hot rolled to a thickness of $4 \mathrm{~mm}$. The chemical composition after hot rolling was determined using inductively coupled plasma optical emission spectroscopy combined with atomic absorption spectroscopy (see Table I). The rolled lumbs were soft annealed at $873 \mathrm{~K}$ for $1.5 \mathrm{~h}$ yielding a microstructure of spherical cementite particles (of diameter $\approx 2 \mu \mathrm{m}$ ) in a ferrite matrix.

Specimens from the $\mathrm{Fe}-0.36 \mathrm{wt} \% \mathrm{C}$ alloy were subsequently austenitized in a salt bath at $1103 \mathrm{~K}$ and quenched in brine to obtain a martensitic microstructure, thus ensuring a more homogeneous distribution of carbon before heating in the electron microscope. The $\mathrm{Fe}-0.71 \mathrm{wt} \% \mathrm{C}$ alloy was in the soft annealed state at the start of the experiments.

TEM specimens were prepared by grinding and polishing plates of dimensions $10 \times 10 \times 1 \mathrm{~mm}$ to a thickness of less than $100 \mu \mathrm{m}$. From these thin plates discs with a diameter of $3 \mathrm{~mm}$ were punched. These discs were thinned by electropolishing at $85 \mathrm{~V}$ using a $10 \%$ perchloric acid/acetic acid mixture at a temperature of $286 \mathrm{~K}$ in a Struers II twin jet polisher.

\section{Experimental procedure}

The specimens were subjected to a heating cycle in a Philips CM30T electron microscope operated at

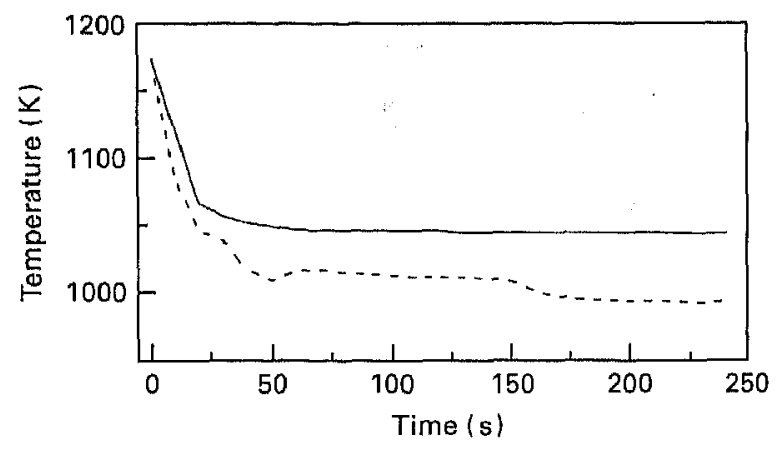

Figure] Typical cooling curves occurring during the experiments of $\mathrm{Fe}-0.36 \mathrm{wt} \% \mathrm{C}$ specimens. The temperatures indicated are those arrived at after cooling. Time is zero corresponds to the time at which cooling is started. $-1044 \mathrm{~K} ;-\cdots 990 \mathrm{~K}$.

$300 \mathrm{kV}$ or in a Philips EM400 electron microscope operated at $120 \mathrm{kV}$. The specimens were heated using a Gatan single-tilt or a Gatan double-tilt heating holder. The temperature was continuously registered using a $\mathrm{Pt} / \mathrm{Pt} 10 \% \mathrm{Rh}$ thermocouple connected to the ring furnace in the holder. The specimens were austenitized in the microscope at temperatures between $1100 \mathrm{~K}$ and $1200 \mathrm{~K}$ for 5 to $10 \mathrm{~min}$ and subsequently cooled down to the transformation temperature, which is in the range $980-1040 \mathrm{~K}$. The cooling rate of the specimen is limited by the heat loss due to radiation and the cooling rate of the furnace. Typical cooling curves are shown in Fig. 1. The maximal cooling rate for this temperature change was about $5-10 \mathrm{Ks}^{-1}$. The transformation experiments were performed isothermally allowing the observation of moderately fast moving interfaces. In preliminary continuous cooling experiments transformation was only observed at a degree of undercooling such that when the transformation was finally observed the migration rates of the transformation interfaces became unacceptably high.

Ferrite-austenite interfaces were distinguished from bending contours by changing the contrast conditions through tilting of the specimen Bending contours moved reversibly during tilting whereas ferrite-austenite interfaces and grain boundaries did not change position. The ferrite-austenite interface was distinguished from grain boundaries both by the microstructure and by electron diffraction. The austenite showed a significantly larger number of stacking faults and twinned regions than ferrite. Using convergent beam electron diffraction ferrite was discriminated from austenite by measuring angles between different zone axes. A single beam direction was not enough for the discrimination of ferrite and austenite, since the Kikuchi-lines of different reflections in ferrite and austenite can appear very similar. A definite allocation of

TABLE I Chemical composition (wt \%) of the Fe-C alloys employed as determined by inductively coupled plasma optical emission spectroscopy combined with atomic absorption spectroscopy. The uncertainty in the carbon concentration is $0.03 \mathrm{wt} \%$

\begin{tabular}{lllllllllll}
\hline Alloy & $\mathrm{C}$ & $\mathrm{Mn}$ & $\mathrm{Cr}$ & $\mathrm{Cu}$ & $\mathrm{Ni}$ & $\mathrm{S}$ & $\mathrm{P}$ & $\mathrm{Mo}$ & $\mathrm{Sn}$ \\
\hline 1 & 0.36 & 0.001 & $<0.001$ & 0.02 & 0.005 & 0.002 & $<0.001$ & 0.001 & $<0.001$ \\
2 & 0.71 & $<0.002$ & 0.05 & $<0.002$ & $<0.008$ & $<0.005$ & $<0.01$ & $<0.01$ & $<0.002$ \\
\hline
\end{tabular}


the crystal structure on either side of the interface during the transformation could therefore not be obtained. Ascribing the moving boundaries to the effect of the transformation investigated, and not, for instance, to recrystallization, is only possible from comparison of diffraction patterns of a specific region before and after the in-situ annealing. The annealing experiments were performed using bright field illumination only.

During the annealing some carbon may be lost from the specimen due to the vacuum conditions which are relatively poor for the material at the temperature investigated. Yet it was clear that not all carbon had evaporated from the specimen, since in several experiments, even after about 50 min of operation at elevated temperatures, the formation of pearlite colonies was still observed during cooling of the specimen to room temperature.

A VHS video recorder connected to the TV-circuit on the microscopic was used to record the images during the experiments. Separate video frames were reproduced afterwards by photographing the television screen. The magnification of the images on the video tapes was calibrated by comparing electron micrographs, photographically obtained at well-defined magnifications, to the images recorded on video tape. The field of view during the experiments was typically 5 by $5 \mu \mathrm{m}$. The migration rates were measured by dividing the distance travelled by the travelling time.

\section{Observations}

While hot stage TEM was expected to allow the observation of both nucleation and growth of ferrite in an austenite matrix, nucleation was never observed. This may result from the influence of the free surface on nucleation in the electron transparent, i.e. very thin, region. In all experiments a transformation front was observed which entered the field of view. The present study is therefore restricted to growth phenomena.

\subsection{Interface migration}

The migration of a phase boundary or a transformation interface involves the trainsfer of atoms from one phase to the other (see Fig. 2). In some cases the atoms can cross the interface at any position of that interface, and the interface effectively migrates perpendicular to the interface, i.e. the normal mode. This mode of growth is common for incoherent interfaces. In the case of (semi) coherent interfaces the interface is relatively immobile. In such a case transfer of the atoms from the one phase to the other phase is only possible at ledges in the interface which consequently proceed parallel to the interface, i.e. the lateral mode. The ledges can be considered as small, mobile interfaces [19].

Both normal and lateral growth modes were observed during the experiments. The classification of the observed interface movement as lateral growth depends on the magnification used and on the orientation of the interface with respect to the electron beam
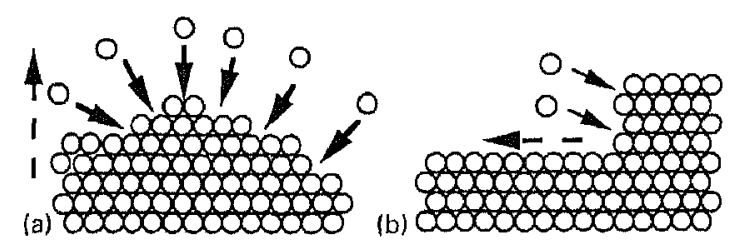

Figure 2 Schematic drawing of interface migration by addition of atoms (a) at any position of the interface; normal mode and (b) at specific positions of the interface; lateral mode. The dashed arrows indicate the direction of the moving (local) interface.

in the experiment. In the case of very small ledges or interfaces moving at a shallow angle with respect to the incident electron beam an interface moving in a lateral mode can be classified erroneously as an interface moving in a normal mode. In the following all cases where no ledges were observed will, by definition, be classified as growth of the "normal mode".

In most observations the interface movement was of the normal mode. The interface moved sluggishly, with periods of a more or less constant velocity, followed by periods of acceleration or decelaration. Often the acceleration or deceleration of the interface could be related to a temporary interaction of the interface and neighbouring local microstructural features.

The morphology of the interfaces varied between smoothly curved and nearly straight. The curved interfaces were more mobile than the straight interfaces. In some cases the straight interfaces were immobile. It was frequently observed that curved interfaces converted into segmented straight interfaces. The displacement of the interface occurred by movement of groups of neighbouring segments. With proceeding transformation segments participated first in one group, then in others that either moved or were sessile. By segmentation of the interface into smaller parts, the interface seemed to circumvent local obstacles as efficiently as possible. A typical example of a segmented interface is shown in Fig. 3 for an Fe-0.71 wt \% $\mathrm{C}$ specimen transforming at $1053 \mathrm{~K}$. According to the $\mathrm{Fe}-\mathrm{C}$ phase diagram no austenite-ferrite transformation can occur at this temperature. However, as the transformation was observed almost $6 \mathrm{~h}$ after first heating the specimen, substantial decarburization could have taken place making the austenite-ferrite transformation possible.

In a few cases growth of the lateral mode was observed. An example of an interface containing ledges is shown in Fig. 4. This period of lateral growth took place between two periods of growth of the normal mode; see Sections 4.2 and 4.3.

The maximum values observed for the migration rate of the interfaces moving in the normal mode and in the lateral mode, taken as the migration rate of the ledges, are shown in Fig. 5 for different $\mathrm{Fe}-0.36 \mathrm{wt} \%$ $\mathrm{C}$ specimens as a function of the transformation temperature. In this figure the maximum rates rather than average values have been presented, since these maximum values are most likely to be the "true" interface velocity not affected by pinning forces. The migration rates of the ledges during growth of the lateral mode are generally higher than the migration rates observed for growth of the normal mode. 


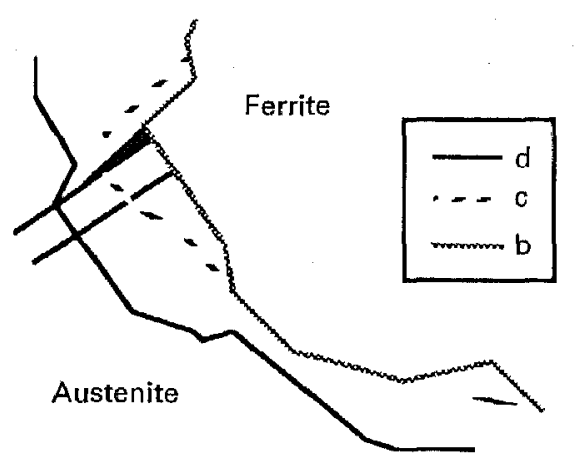

(a)

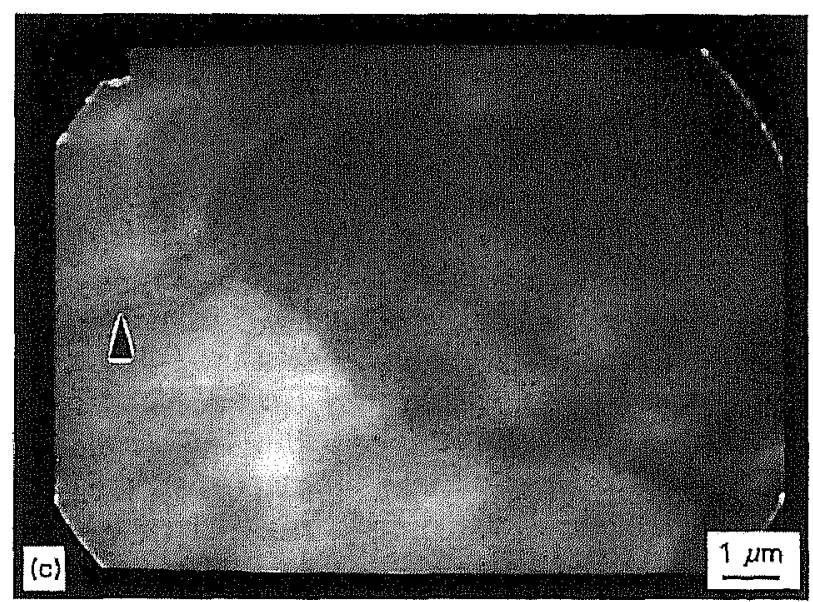

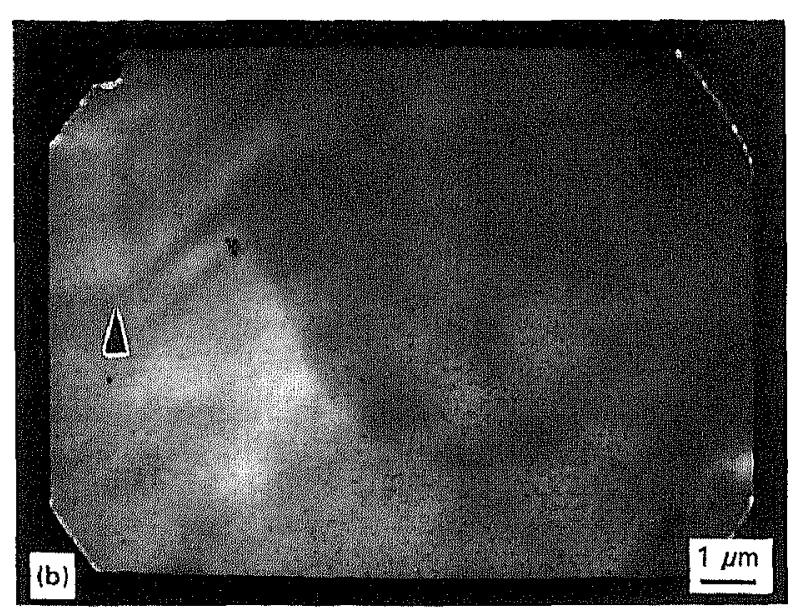

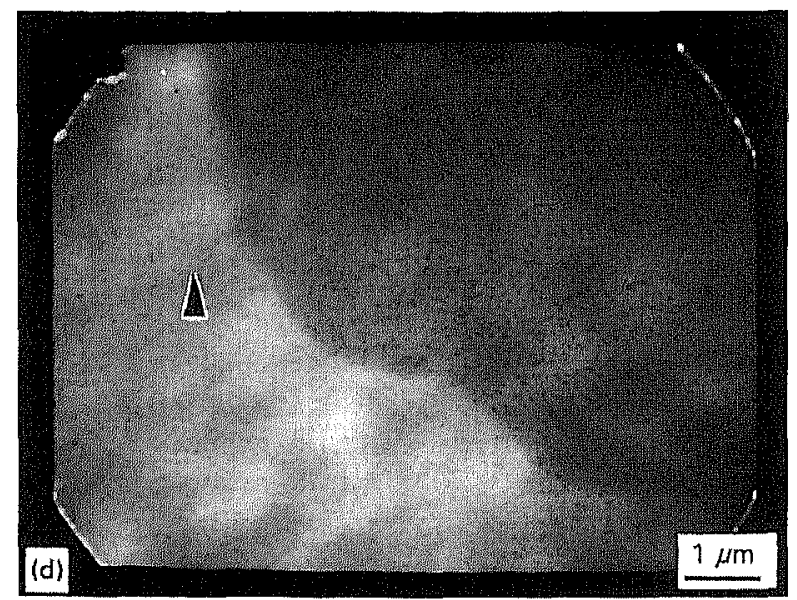

Figure 3 Growth of the normal mode observed during transformation from austenite to ferrite in an $\mathrm{Fe}-0.71 \mathrm{wt} \% \mathrm{C}$ alloy. The spikes indicated by the arrow hend as a common point of reference, are likely to be stacking faults in the austenite. (a) Schematic diagram of the interface positions in b-d. (b) The ferrite growing from the top-right position. (c) The same interface recorded $1 \mathrm{~s}$ alter (b). (d) Again as (b) but now after $3 \mathrm{~s}$. The scale marker indicates a length of $1 \mu \mathrm{m}$.

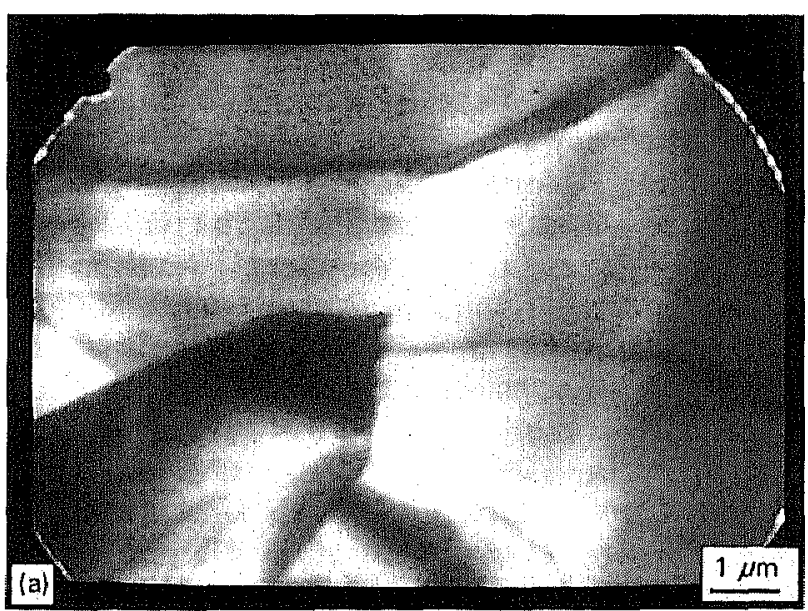

The migration rates measured do not seem to depend significantly on the transformation temperature. The scatter in the maximum migration rates may be due to observation problems as caused by variations of the local specimen thickness or variations of the foil normal (see also section 5.1). The migration rates of the interface in the lateral mode in Fig. 5 equal the migration rate of the ledges. The migration rate of the interface normal to the direction in which the ledges move, $v$, can be calculated from the migration rates of the ledges $\left(v_{s}\right)$, the height of the ledges $(d)$ and the
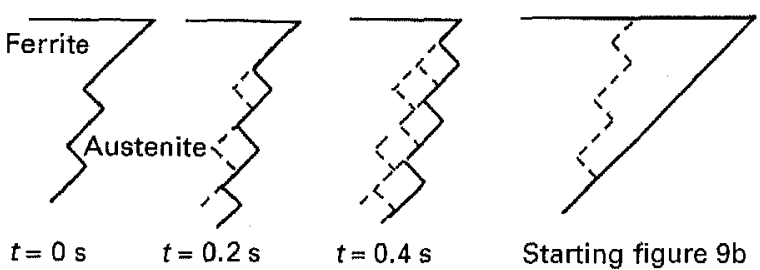

(b)

Figure 4 (a) Micrograph of an interface moving in the lateral mode during the transformation from austenite to ferrite in an $\mathrm{Fe}-0.36 \mathrm{wt} \% \mathrm{C}$ alloy at $1021 \mathrm{~K}$. The ledge height was $100 \mathrm{~mm}$. (b) Schematic diagram of the positions of the ledges at three limes of the transformations. The final position corresponds to the morphology shown in Fig. 9(b). The scale marker indicates a length of $1 \mu \mathrm{m}$.

density of those ledges $\left(n_{\mathrm{s}}\right): v=d n_{\mathrm{s}} v_{\mathrm{s}}$. The density of the ledges will be dependent on the nucleation of those ledges at the interface considered and is expected to be a function of the interface structure. For the number of ledges per unit of length and the height of the ledges for the transformation front shown in Fig. 4 it can be calculated that the velocity of the interface normal to the direction in which the ledges move is $0.2 \mu \mathrm{m} \mathrm{s}^{-1}$. This is lower than the velocity of the ledges, which equals $0.5 \mu \mathrm{ms}^{-1}$. It should be stated that the transformation behaviour observed showed a large 


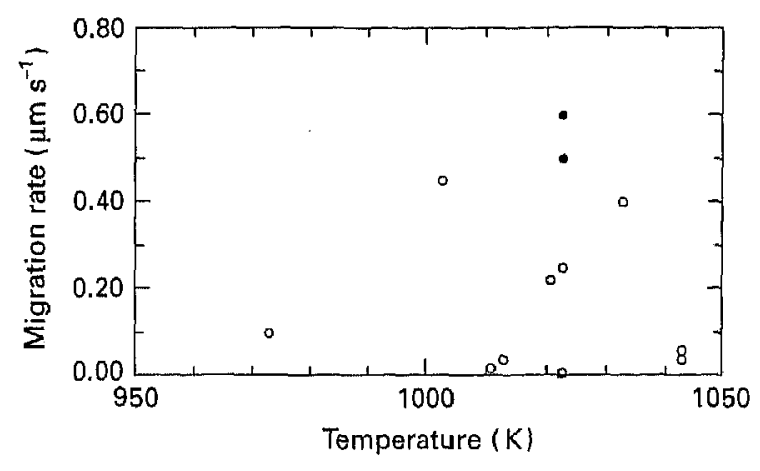

Figure 5 Maximum migration rates of transformation interfaces for growth of the normal $(O)$ and lateral $(0)$ modes during isothermal anneal of $\mathrm{Fe}-0.36 \mathrm{wt} \% \mathrm{C}$ specimens. The lateral rate corresponds to the migration rate of the ledges.

variation. However, based on a larger number of observations some general conclusions, illustrated using individual experiments can be drawn.

\subsection{Influence of dislocations and grain boundaries on the rate and direction of migration of transformation interfaces}

Local constituents of the microstructure, e.g. dislocations, stacking faults, grain boundaries and precipi- tates may influence the migration rate of the interface. They can accelerate or decelerate the interface and/or alter its direction of movement, without a noticeable effect on the migration rate.

The interaction of dislocations and the transformation interface showed large variations. In some cases the dislocations became active and moved parallel to or away from the approaching interface. Other dislocations remained immobile and were annihilated at the interface. In most cases the interface decelerated in the vicinity of dislocations, but cases of acceleration were also observed.

Surprisingly, grain boundaries did not seem to have a significant effect on the rate of migration. However, they did have a strong effect on the direction in which the transformation interface moved. In many cases a nose developed in the transformation interface at the grain boundary encountered dragging the remaining interface along, while following the course of the grain boundary. Typical examples of the role of the grain boundaries are shown in Figs 6 and 7. Sometimes the interface accelerated on nearing a grain boundary; however, such accelerations were only temporary and similar to those observed in the absence of grain boundaries.

An orienting effect of grain boundaries was also observed around low energy boundaries, such as twin

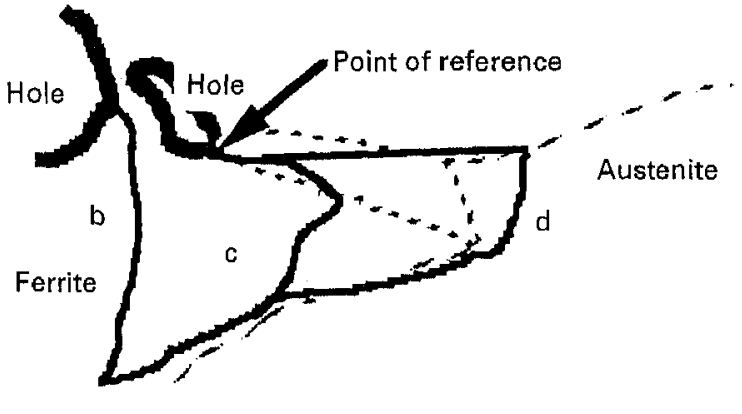

- - Austenite grain boundaries

(a)

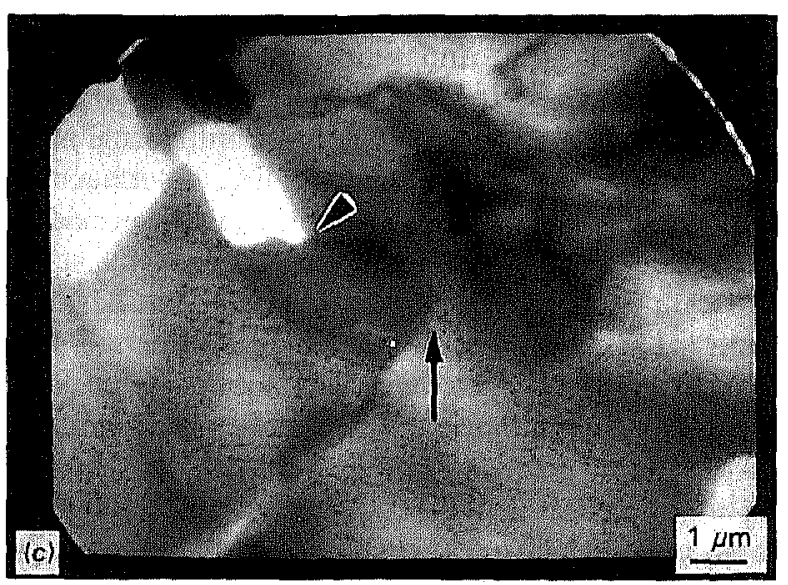

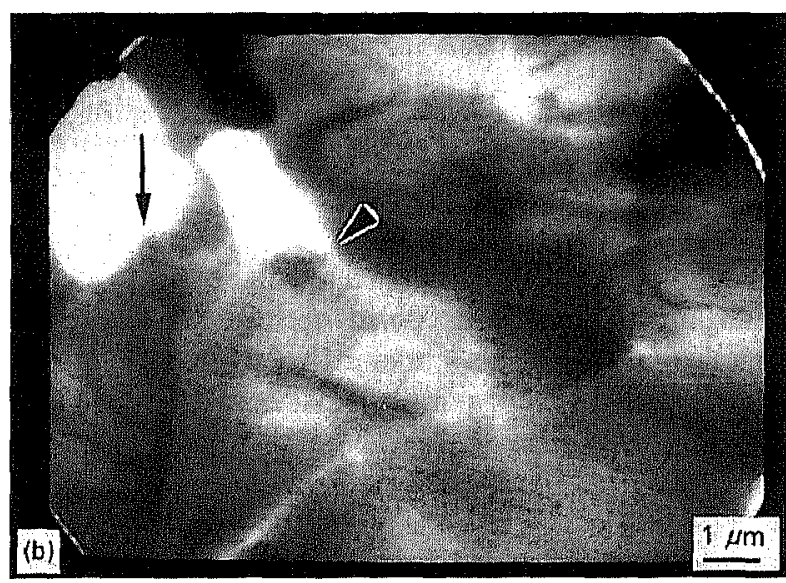

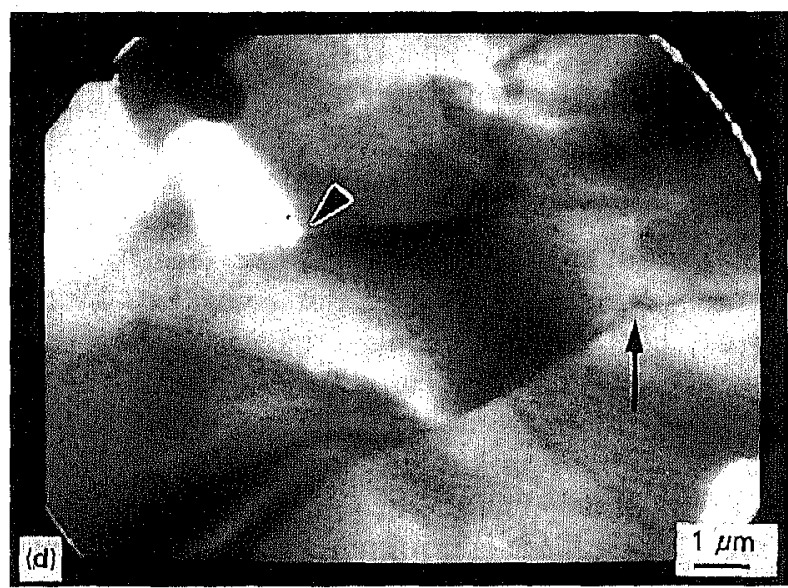

Figure 6 Interaction of austenite grain boundaires and a moving interface in an $\mathrm{Fe}-0.36 \mathrm{wt} \% \mathrm{C}$ alloy observed at $1021 \mathrm{~K}$. (a) Schernatic diagram. The dashed lines indicate the austenite grain boundaries. The arrow head indicates a point of reference. The arrow indicates the position of the interface. The micrographs were taken at $18 \mathrm{~s}(\mathrm{~b}), 27 \mathrm{~s}$ (c) and $34 \mathrm{~s}$ (d) where $t=0$ corresponds to $818 \mathrm{~s}$ after the start of cooling. 

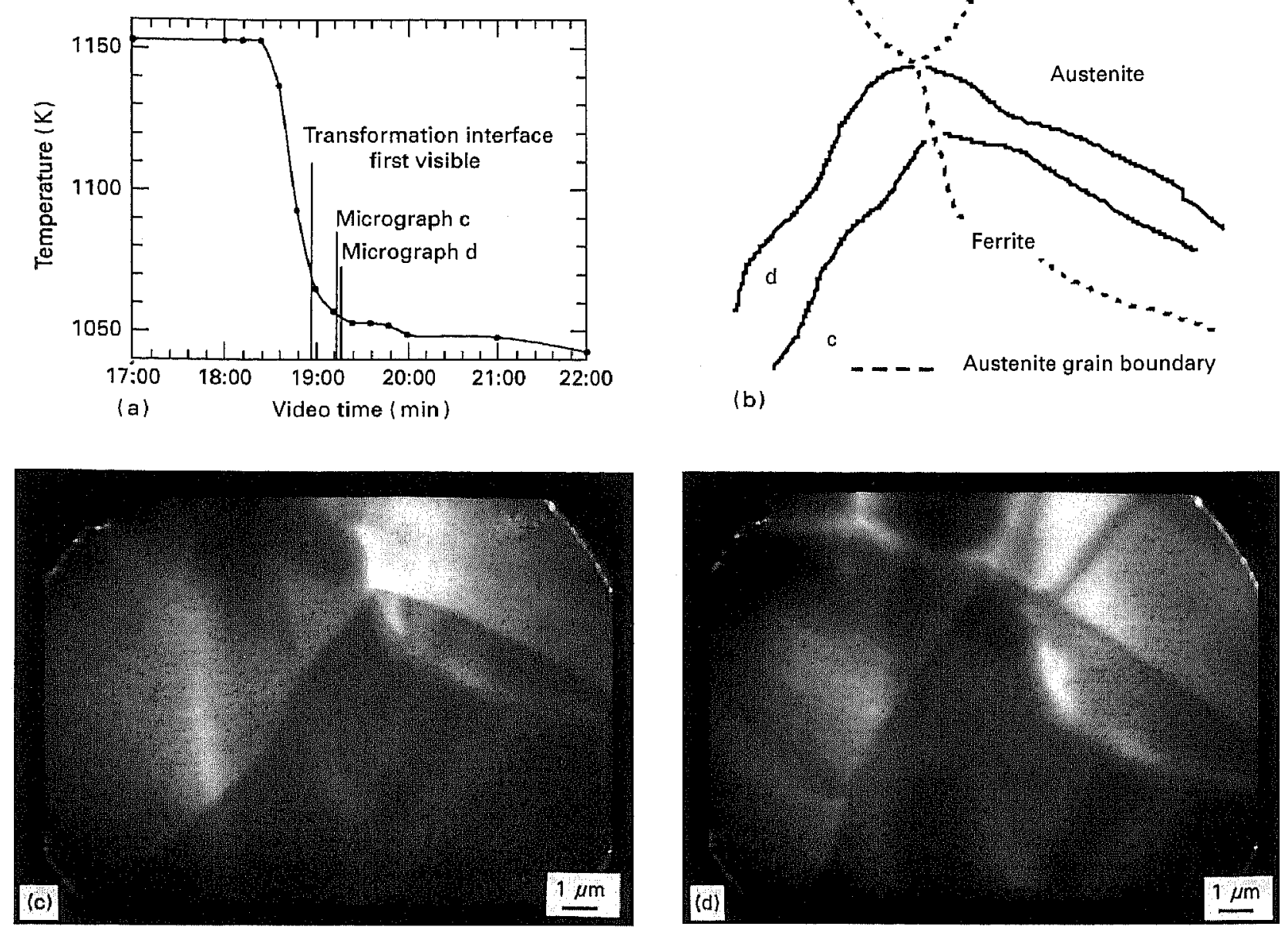

Figure 7 Transformation from austenite to ferrite in an $\mathrm{Fe}-0.36 \mathrm{wt} \% \mathrm{C}$ alloy on cooling at approximately $1055 \mathrm{~K}$. The times at which the photographs are taken are shown in (a). A schematic representation of the migration of the interface at the times corresponding to micrographs (c) and (d) is given in (b). The scale marker indicates length of $1 \mu \mathrm{m}$.

boundaries in austenite (see Fig. 8). In this case a transformation interface approached a twin boundary under a certain angle, about $90^{\circ}$ in the figure. Instead of directly crossing the boundary, the transformation interface first moved parallel to the boundary (see Fig. 8(b-d) and finally crossed it after Fig. 8(d) was taken. Despite the very low energy of the boundary, the twin boundary was capable of changing the direction of movement of the transformation interface.

\subsection{Relation between foil bending processes and the migration rate of interfaces}

During several annealing experiments it was observed the bending of the foil, typically over a few degrees, took place at both sides of the interface during a deceleration period. The bending was recognized by the activity of the bending contours. Each bending contour is associated with a certain set of reflecting lattice planes which is precisely in the Bragg position for diffraction in the dark regions of the bending contour in the bright field image. The precise way in which the bending took place is not known since the operative reflection associated with the bending contour was not determined.

The stresses can be the result of the difference between the specific volumes (volumes per iron atom) of the two phases on either side of the interface and/or temperature gradients in the foil. As will be explained in Section 5.2 the latter type of stress is considered to be of little importance.

A typical example of the activity of bending contours near the transformation interface is shown in Fig. 9. In this experiment an $\mathrm{Fe}-0.36 \mathrm{wt} \% \mathrm{C}$ specimen was austenitized at $1103 \mathrm{~K}$ and subsequently annealed at $1021 \mathrm{~K}$. The transformation was observed over a period of $700-1600 \mathrm{~s}$ after cooling to the transformation temperature. An interaction of the transformation interface and the bending contours was observed in the period of 818 to 878 s. Fig. 9(a) schematically indicates the position of the interface during deceleration shown in Fig. 9(b-d). Fig. 9(e) schematically depicts the relevant features during the period of immobility of the interface (Fig. $9(f-h)$ ). In the schematic drawings some of the characteristic bending contours visible in the electron micrographs are also indicated. The measured interface velocity is depicted in Fig. 10 versus the times at which each micrograph was taken. It can be seen from Fig. 10 that the interface velocity decreases from $0.13 \mu \mathrm{ms}^{-1}$ to nil. The change in interface velocity was accompanied by a change in the position of the bending contours at the interface and the formation of new contours. The ferrite grain, initially growing in the lateral mode (see Fig. 4) entered a region in the austenite where bending contours 


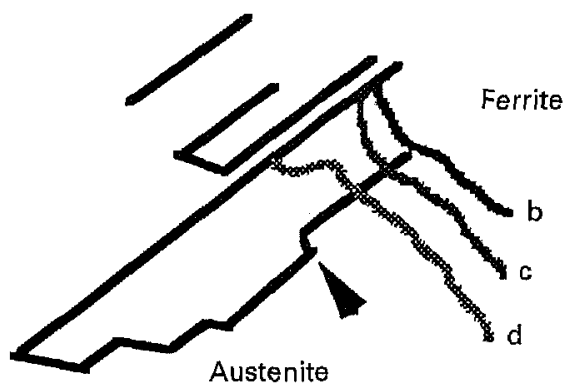

(a)

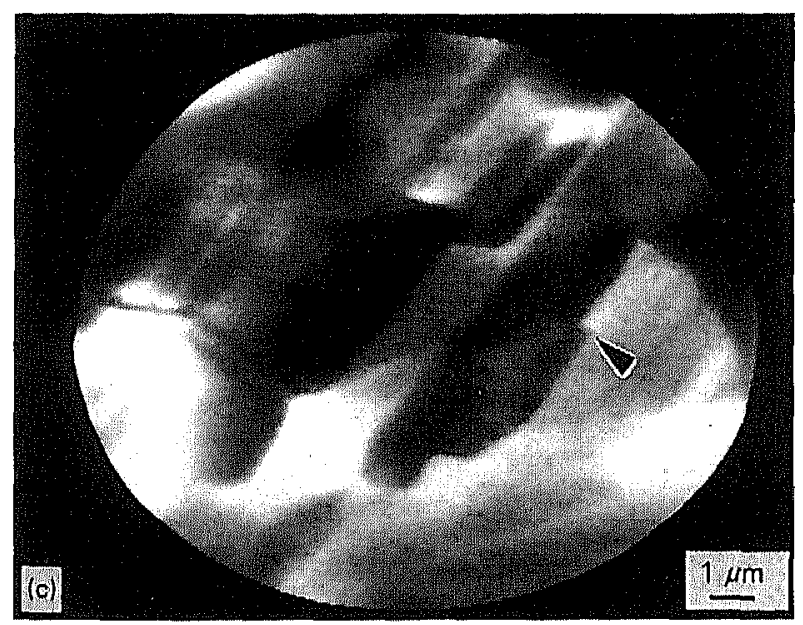

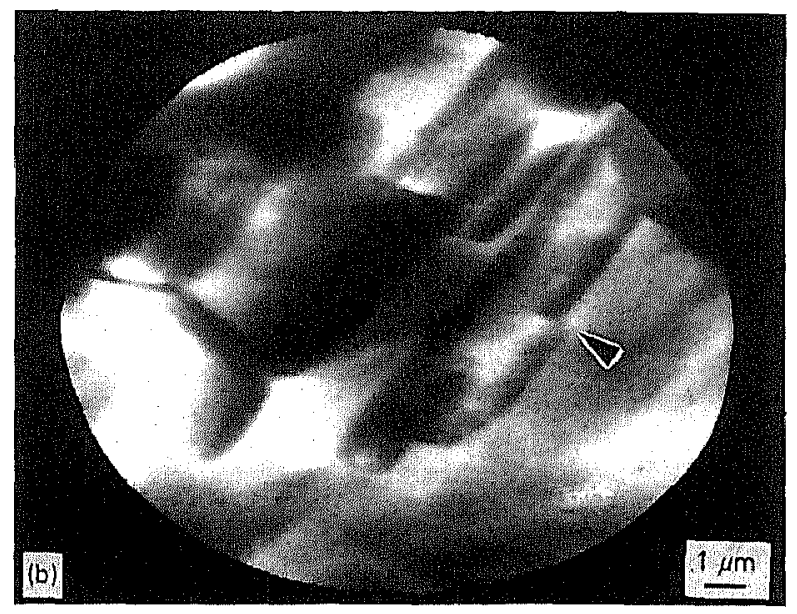

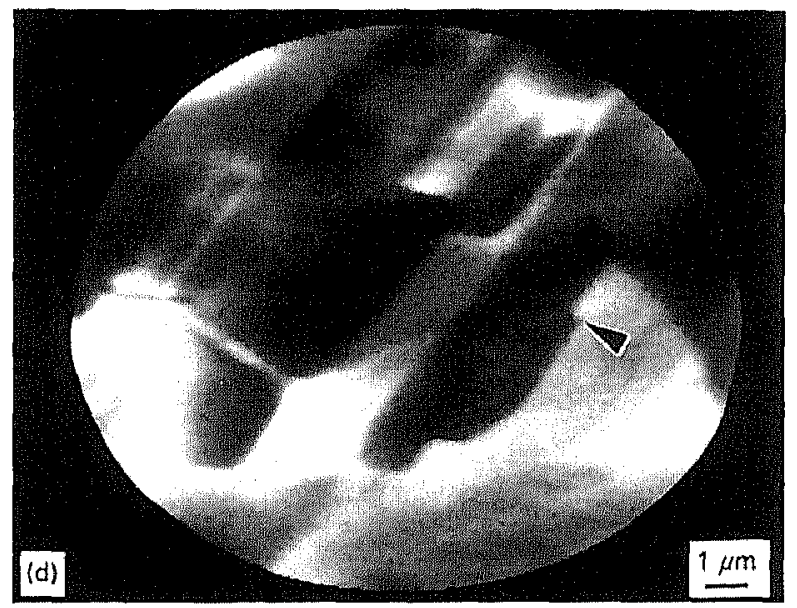

Figure 8 Transformation from austenite to ferrite in an Fe-0.36 wt \% C alloy at a temperature of $973 \mathrm{~K}$ showing the position of the transformation interface during interaction of the transformation interface and a twin boundary. (a) A schematic diagram; the bold straight line segments represent twin boundaries. (b) At $t=3 \mathrm{~s}$ after first noticing the transformation. (c) Again at $t=5 \mathrm{~s}$. (d) Again at $t=10 \mathrm{~s}$. The arrowhead indicates a point of reference. The scale marker indicates a length of $1 \mathrm{\mu m}$

were present (dark region at the top of Fig. 9(b). Further growth took place in the normal mode parallel to the bending contours (in the micrographs to the right hand side). The horizontal segment of the interface remained stationary. As the tip advanced a thin stress contour parallel to the thicker contour in the austenite moved in the direction of the interface (see the arrows in Fig. 9(b) and label b in Fig. 9(a)). After contacting of the bending contour with the transformation interface a new circular bending contour around the tip of the interface arose (see the dotted region labelled by c in Fig. 9(a) and Fig. 9(c)). As soon as the tip was fully surrounded by this new bending contour, the interface migration strongly decreased, as is shown in Fig. 10. Yet the interface continued to migrate, but the normal growth mode was replaced again by the lateral mode, The ledges originated from the lower part of Fig. 9(d) and their direction of movement is indicated by the arrow in Fig. 9(d). The region in austenite enclosed by the bending contour increased with continued migration of the interface. Outside the enclosed region a jerky motion of dislocations was observed suggesting plastic deformation of the austenite.

During the period of lateral growth the foil bent in such a way that the circular bending contour and the bending contour parallel to the immobile segment of the transformation interface met in the austenite. Before this happened mobile dislocations were observed in the region between both contours. The region of darker contrast, enclosed by the circular bending contour, increased until growth stopped completely at a time between Fig. 9(d) and (f). After a period of almost $1 \mathrm{~min}$, migration in the normal mode recommenced. Prior to the re-occurrence of migration the bending contours in the austenite changed position indicating a continuing change of the bending of the foil. Intermediate stages during this period are drawn schematically in Fig. 9(e). Dislocation movement was observed, both near the tip of the interface and further away from the interface. After some time the upper bending contour and the contour concentrated around the tip separated again, as shown in Fig. 9(f) and $(\mathrm{g})$. Just before the separation took place an increased activity of dislocations around the breakaway point was observed (see Fig. 9(g)). Eventually, the circular bending contour in austenite disappeared at the interface and the interface regained mobility. Movement of bending contours in the ferrite as well as the movement of dislocations in ferrite near the transformation interface was observed. The bending contours in the ferrite appeared to be more active than those in the austenite. The bending contours both 
drifted and rotated. This implies that the orientation of the ferrite changed with respect to the electron beam direction, as a result of bending of the foil during the process. This was even more discernible during the period of immobility of the interface.

\section{Discussion}

\subsection{Interface mobility}

In this section the experimental values for the maximum migration rates are compared to the values for the interface migration rates as predicted for the cases of diffusión controlled migration.and interface controlled migration. In the first case the transport of solute ahead of the interface determines the rate at which the transformation interface can migrate. In the second case the interface properties themselves determine the migration rate.

\subsubsection{Diffusion controlled migration}

Diffusion controlled migration (DCM) of the interface implies that the velocity of the interface is determined

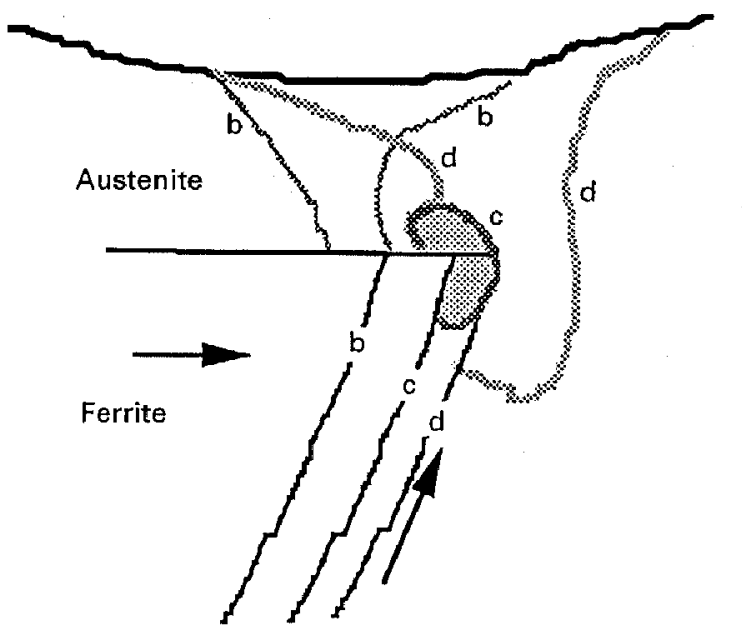

(a)

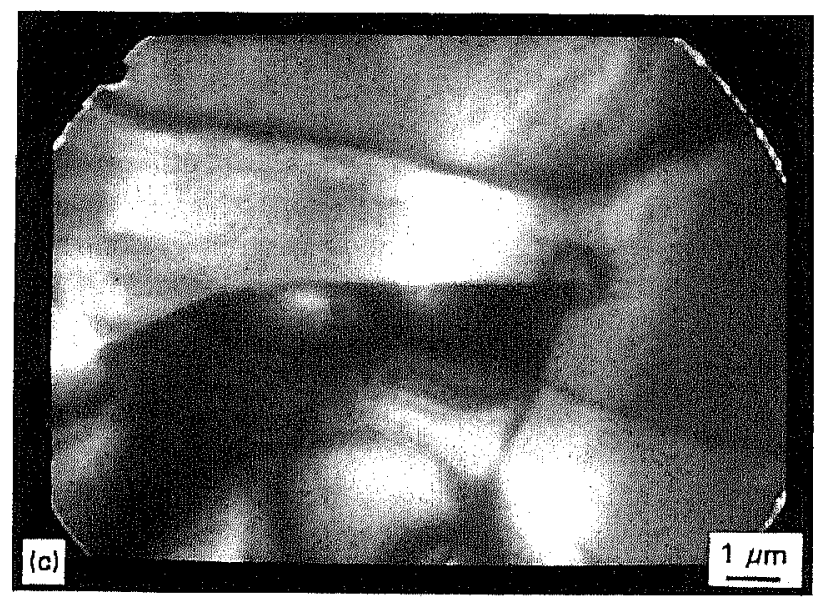

by a (carbon) mass balance: see Equation 1 for the one-dimensional case, where the migration of the interface is coupled with the flux of carbon away from the interface

$$
\left(c^{\gamma \alpha}-c^{\alpha \gamma}\right) \frac{\partial z}{\partial t}=-D_{\mathrm{C}}^{\gamma}\left(\frac{\partial c}{\partial z}\right)_{z \downarrow Z}
$$

with $Z$ the location of the interface, $z$ the co-ordinate normal to the moving part of the interface (for $z>Z$ : austenite), $t$ the transformation time, $\partial z / \partial t$ the migration rate of the interface, $D_{\mathrm{C}}^{\gamma}$ the concentration dependent diffusion coefficient of carbon in austenite, $c^{\gamma \alpha}$ the concentration of carbon in austenite at the interface, $c^{\alpha_{\gamma}}$ the concentration in ferrite at the interface and $c$ the carbon concentration in the austenite. The diffusion of carbon in austenite is governed by Fick's second law

$$
\frac{\partial c}{\partial t}=\frac{\partial}{\partial z}\left(D_{\mathrm{C}}^{\gamma} \frac{\partial c}{\partial z}\right)
$$

The coupled differential equations (Equations 1 and 2) can be solved numerically to yield the migration rate
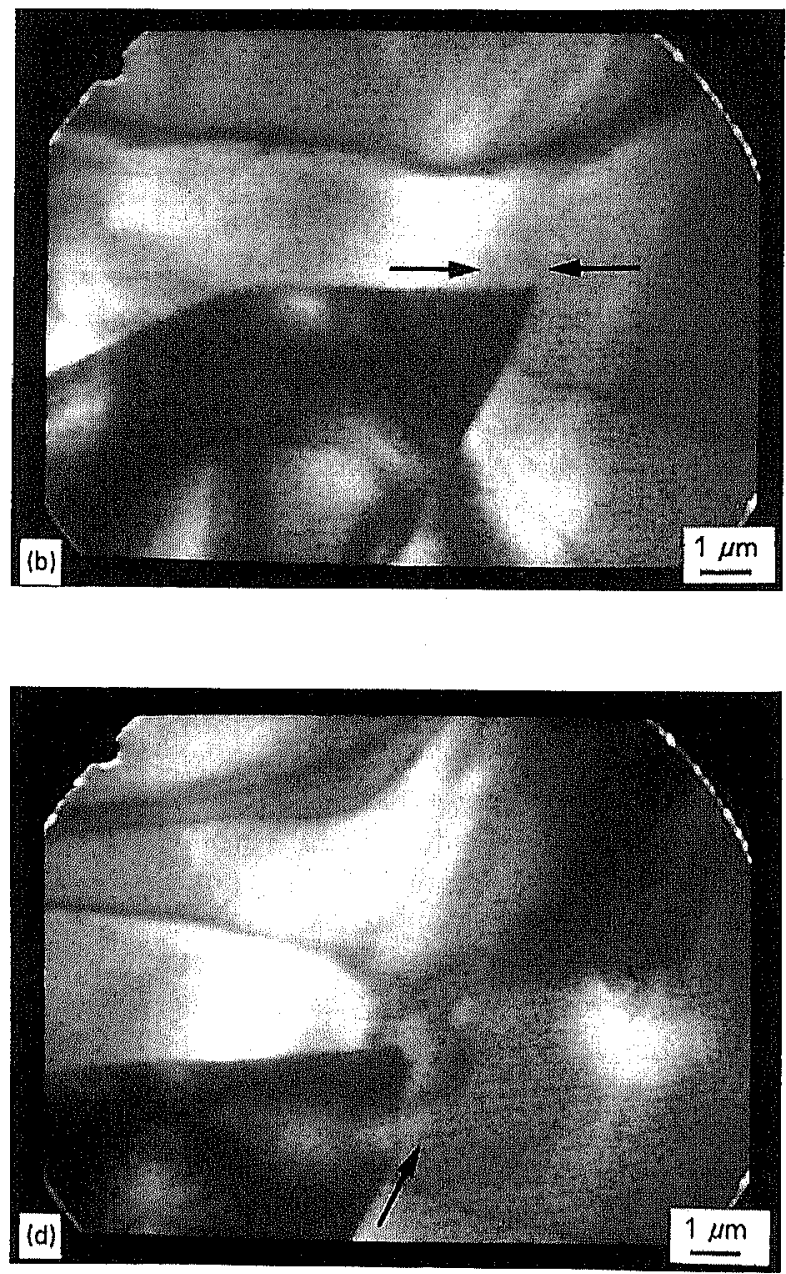

Figure 9 (a) Schematic diagram showing migration of a transformation interface during transformation from austenite to ferrite in an $\mathrm{Fe}-0.36 \mathrm{wt} \% \mathrm{C}$ alloy at $1021 \mathrm{~K}$. (b) At time $t=0$ (which corresponds to $818 \mathrm{~s}$ after the cooling was started), (c) after 3 , (d) 8 , (f) 41 , (g) 49 and (h) $65 \mathrm{~s}$. The arrows in (b) indicate the position of the bending contours. The arrow in (d) indicates a ledge moving towards the tip. The arrow in (g) indicates the activity of dislocations (see text for detailed description, and Fig. 10 for corresponding interface velocity). The scale marker indicates a length of $1 \mu \mathrm{m}$; (e) indicates schematically the features of micrographs $f-h$. 


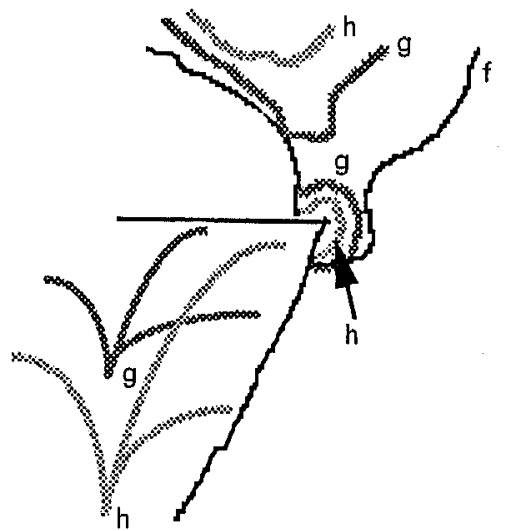

(e)

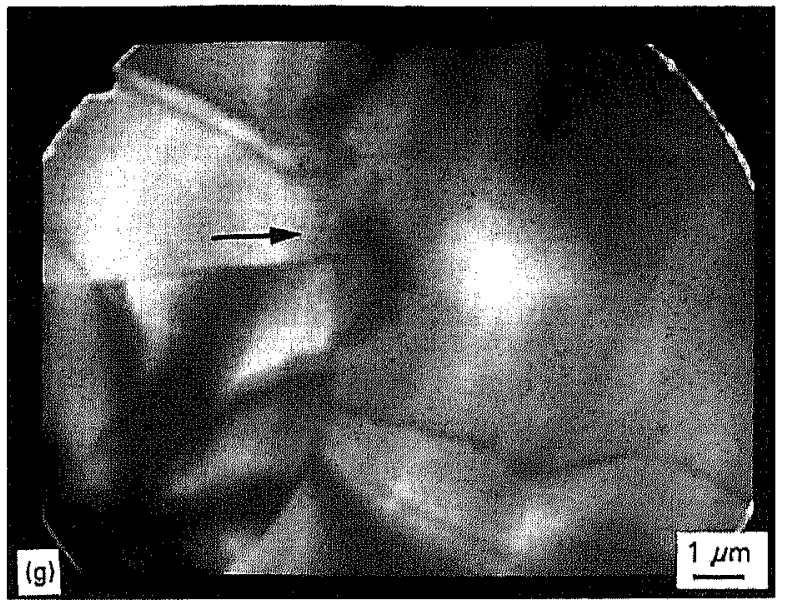

Fig!re 9 Continued

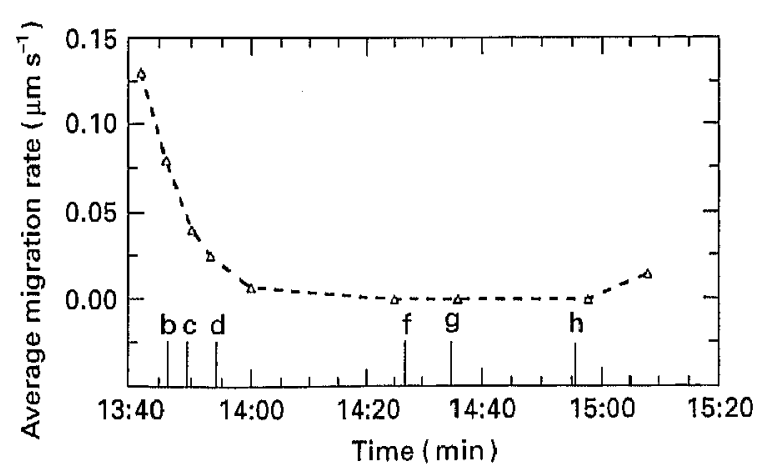

Figure 10 Migration rate of the interface as a function of the transformation time in the time region corresponding to the micrographs in Fig. 6. The times indicated by the bars at the base of the figure correspond to the appropriate micrographs in Fig. 9.

[20]. Note that the migration rate, $\partial z / \partial t$, is perpendicular to the moving part of the interface; i.e. it can pertain to normal growth and it can pertain to lateral growth (then $\partial z / \partial t$ is parallel to the overall interface and perpendicular to the moving ledge).

In general, a lower initial carbon concentration of the austenite enhances the migration rate due to a larger carbon-concentration gradient at the interface. Hence, in the case of diffusion controlled migration, decarburization of the specimen during the experiment will lead to an increased migration rate.
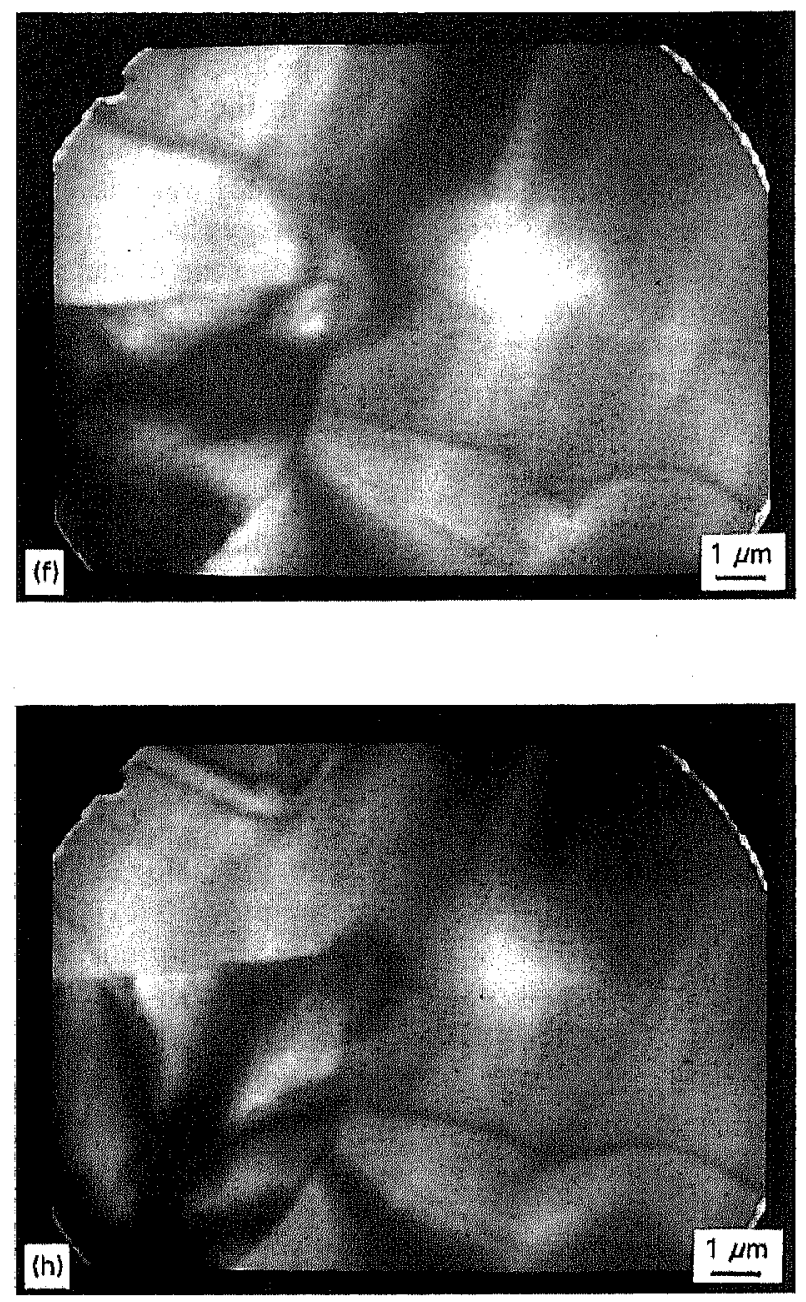

\subsubsection{Interface controlled migration}

In the case of interface controlled migration (ICM) the migration rate of the interface can be described as a function of the atom transfer across the interface [19]. For relatively small values of the Gibbs free energy change, $\Delta G$, accompanying this transfer, i.e. $\Delta G / R T \ll 1$, it holds that

$$
\frac{\partial z}{\partial t}=\frac{M}{V_{\mathrm{m}}} \Delta G
$$

where $M$ is the mobility of the interface, $\Delta G$ the Gibbs free energy change for a mole of transforming alloy and $V_{\mathrm{m}}$ a mean molar volume of the initial and final phases in the transformation. This migration rate can also pertain to normal and lateral growth (see remark below Equation 2).

For the mobility of an incoherent boundary in a single phase material, Turnbull [21] suggested that the grain boundary diffusion should be assumed to be the rate controlling mechanism for the atom transfer across the interface. Then, the mobility becomes

$$
M=\frac{\delta_{\mathrm{b}} D_{\mathrm{i}} V_{\mathrm{m}}}{b^{2} R T}=\frac{\delta_{\mathrm{v}} V_{\mathrm{m}}}{b^{2} R T} D_{0} \exp \left(-\frac{Q}{R T}\right)
$$

where $\delta_{\mathrm{b}}, b, D_{\mathrm{i}}$ and $Q$ are the thickness of the interface, the interatomic distance, the diffusivity of the atoms 
along the grain boundary, and the activation energy for grain-boundary diffusion, respectively.

To estimate the migration rate in the $\mathrm{Fe}-\mathrm{C}$ alloys under investigation, the reported data for the mobility of incoherent interfaces in pure $\mathrm{Fe}$ [22] were used in combination with the Gibbs free energy change of the $\mathrm{Fe}-0.36 \mathrm{wt} \% \mathrm{C}$ alloy calculated using the model described in [23]. It thus follows

$$
\frac{\partial z}{\partial t}=-5.91 \times 10^{5} \exp \left(-\frac{19605}{T}\right) \underset{\left(\mu \mathrm{ms}^{-1}\right)}{\Delta G_{\mathrm{Fe}-0.4 \mathrm{C}}^{\gamma \alpha}}
$$

with $\Delta G_{\mathrm{Fe}-0.4 \mathrm{C}}^{\gamma-\alpha}$ defined as the Gibbs free energy change (in $\mathrm{J} \mathrm{mol}^{-1}$ ) for one mole of austenite with a carbon concentration of $0.36 \mathrm{wt} \% \mathrm{C}$ that transforms into ferrite and equilibrium austenite (see [23] for the exact definition of $\Delta G_{\mathrm{Fe}-0.4 \mathrm{C}}^{\gamma^{+\alpha}}$ ). This Gibbs free energy change does not include contributions from either misfit strains or free surfaces of the thin foil. In view of the present results such contributions might be significant (see also Section 5.3).

\subsubsection{Comparison of predicted and experimental migration rates}

The migration rates of transformation interface as calculated for DCM and ICM are shown in Fig. 11, together with the values determined experimentally both for the normal and lateral growth modes; experimental data from [17] are included as well. The values for the migration rate under DCM or ICM are the maximum values possible. The values for DCM were calculated for the initial stages of the transformation where the carbon concentration gradient was maximal. The values for ICM were calculated for an incoherent, unpinned interphase boundary. Any form of pinning or (semi)-coherency of the interface will lead to a lower migration rate. The interface velocity as calculated for DCM decreases moderately with increasing temperature (because of a lower concentration of carbon in austenite at the interface) and decreases with increasing gross carbon concentration

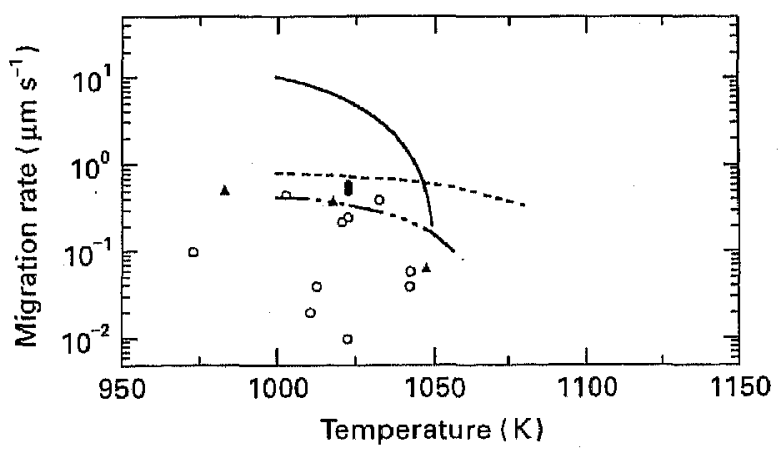

Figure $1 /$ Migration rate of the interface as determined experimentally for growth in the normal mode and the lateral mode for the initial $\mathrm{Fe}-0.36 \mathrm{wt} \% \mathrm{C}$ alloy compared to theoretical values predicted for ICM or DCM (for an initial carbon concentration of 0.2 or $0.36 \mathrm{wt} \% \mathrm{Cl}$ and experimental data on the thickening kinetics of ferrite in $\mathrm{Fe}-0.42 \mathrm{wt} \% \mathrm{C}$ aloy [17]. $\mathrm{O}$ normal rate; lateral rate; $\triangle$ Bradley $0.42 \mathrm{wt} \% \mathrm{C}$; - - DCM $0.2 \mathrm{wt} \% \mathrm{C} ; \ldots$.... DCM $0.36 \mathrm{wt} \% \mathrm{C} ;-$ ICM $0.36 \mathrm{wt} \% \mathrm{C}$. (because of a higher concentration of carbon in the centre of the austenite grain). The values predicted for ICM show a strong decrease with increasing temperature (because of a smaller $\Delta G$ with increasing temperature). The experimental data for the migration rates do not show a clear dependence on the transformation temperature, as discussed in Section 4.1.

The experimental values for the growth rate in the lateral mode for the $\mathrm{Fe}-0.36 \mathrm{wt} \% \mathrm{C}$ alloy, i.e. the migration rate of the ledges, are in fair agreement with the migration rates predicted for DCM for $\mathrm{Fe}-\mathrm{C}$ alloys of similar composition. Such agreement has previously been reported for $\mathrm{Fe}-\mathrm{C}$ alloys of a comparable composition [18] where the lengthening and thickening kinetics of ferrite sideplates as measured by THEEM were compared to the kinetics as predicted for DCM.

In most cases, the experimental values for growth rate in the normal mode are lower than those predicted for DCM. For this difference there may be several reasons:

- measurement of the migration rate in an advanced stage of the transformation when the austenite has become enriched in carbon from already formed ferrite. Then, the corresponding much smaller carbon concentration gradient leads to a lower migration rate of the interface;

- the influence of stress development at the interface as deduced from the present observations, (see Section 5.3);

- a retarding effect due to the interface structure that may decrease the mobility of the overall interface (even to nil, see also $[4,17,18]$ );

- an incorrect classification of some cases of, in reality, lateral growth mode as cases of normal growth mode because of limitations of the resolution at the magnification used. Then it is expected that the observed net migration rate normal to the overall interface is lower than that predicted for DCM (see end of Section 4.1).

\subsection{The effect of grain boundaries on the interface migration}

The austenite-grain boundaries showed an ability to guide the direction of the moving transformation interface (see Figs 8 and 9) but did not lead to an enhanced growth rate along the grain boundary. Generally, growth of ferrite at temperatures just below the transition temperature is considered to be of allotriomorphic nature, i.e. the growth rate along the grain boundary exceeds the growth rate normal to the grain boundary, resulting in a ellipsoidal morphology of the ferrite grains [25]. This morphology was not observed in this work, which can be explained as follows: the formation of ferrite nuclei at the austenite grain boundaries was never observed. The ferrite particles always nucleated outside the field of view. The interface observed belonged to a ferrite particle which had already transformed several other austenite grains; at this stage the characteristic morphology could not be recognized. The small number of ferrite 
nuclei also explains the large periods of time in which the transformation from austenite to ferrite was observed.

\subsection{The influence of stresses on the transformation interface}

During the experiments the transformation interface moved irregularly, which neither follows from the ICM model or from the DCM model. The observed deceleration and acceleration is attributed to stress development and relaxation ahead of the moving interface. The hypothesis is based on the occurrence of bending in the austenite near the transformation interface, as described in Section 4.3.

The local bending of the specimen can be due to specific volume changes during the transformation and/or can be the result of local temperature variations. Temperature variations due to inhomogeneous cooling of the specimen are not really expected, since in the experiment described (Figs 9 and 10) already more than $12 \mathrm{~min}$ had passed after cooling before any transformation was observed, whereas the sample needs only a few minutes to cool down to the transformation temperature. Heating of the specimen by the electron beam or as the result of the heat released by the transformation is considered to be a marginal effect. Note that the transformation temperatures are in the range of $1000-1050 \mathrm{~K}$, corresponding to relatively small undercoolings and thus a relatively small amount of transformation heat. Any heat generated locally will be removed either by radiation or conduction to the surrounding thicker regions of the specimen [26].

Hence, the change of bending of the foil during the transformation is attributed to stresses induced by the transformation. Support for this assumption is the observation that the bending of the observed part of the specimen increased when the transformation front reached the region observed. Furthermore, the movement of dislocations was observed near the transformation front and near the bending contours, mostly just before motion of bending contours. If a dislocation possesses an appropriate Burgers vector and is situated on an appropriate glide plane, the dislocation is capable of relaxing stresses according to the Peach-Koehler equation [27]. Dislocation activity was observed both in the austenite and the ferrite.

The origin of the stress development during the transformation can be understood by examination of the volume per Fe atom in both phases. In Fig. 12 the volume per $\mathrm{Fe}$ atom in austenite and ferrite, using data from [5], is depicted taking the carbon concentration in austenite as the equilibrium carbon concentration at each temperature [28]. The volume per $\mathrm{Fe}$ atom in austenite is a strong function of the carbon concentration. Whereas for temperatures below $1042 \mathrm{~K}$ the initial austenite for an $\mathrm{Fe}-0.36 \mathrm{wt} \%$ $\mathrm{C}$ alloy has a volume per $\mathrm{Fe}$ atom that is smaller than that for ferrite, the volume per $\mathrm{Fe}$ atom at the interface, where the carbon enrichment of the austenite is pronounced, is larger than that for ferrite. The effect of

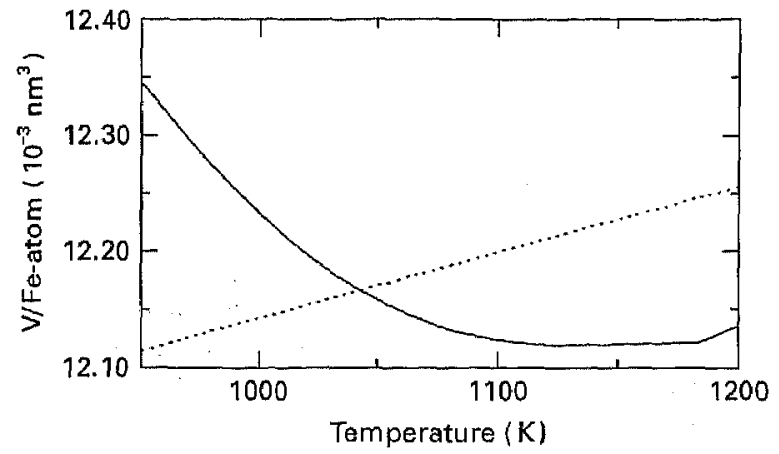

Figure 12 Volume per iron atom for ferrite (--) and for austenite $(-)$ with a carbon concentration according to the GS phase boundary in the accepted $\mathrm{Fe}-\mathrm{C}$ phase diagram [5].

such an appreciable stress development, as a result of a difference in specific volume across the interface, on the transformation process is neglected in the literature $[1,3,4]$.

The development of stresses at the moving interface could explain the observed acceleration and deceleration of the interface. Consider the development of a ferrite nucleus under simultaneous rejection of the carbon. At the interface the carbon concentration in austenite is increased with respect to the initial concentration. As long as the equilibrium composition at the interface is not reached, a driving force for interface migration exists and the interface can migrate. Upon continued migration the carbon concentration in austenite increases and thus the Gibbs free energy difference across the interface decreases (to nil when the equilibrium concentration is reached). During this process the elastic strains near the interface build up, since the volume difference between austenite and ferrite increases with increasing carbon concentration in austenite. Thus, the strain energy in the material near the interface increases; it reaches its highest value when the carbon concentration becomes the equilibrium concentration (if all volume misfit would be accommodated elastically). According to this picture, upon progressing transformation, at the transformation interface a decrease of the difference of chemical Gibbs free energy (driving the transformation) and an increase of strain energy (opposing the transformation) occurs. Thus, the total Gibbs free energy change decreases and the migration rate decelerates and the transformation front can even become (temporarily) immobile. However, the stresses that are built up across the interface can relax during the annealing, not only by the movement of dislocations in the austenite and ferrite (see Fig. $9(\mathrm{~g})$ ) but also by the ongoing diffusion of carbon from the interface into the austenite (even while the interface halts). As a consequence of the latter process the carbon concentration at the interface decreases. Hence, upon continued annealing, the chemical Gibbs free energy change increases and the strain energy decreases. As a result the migration rate increases.

\section{Conclusions}

Hot stage TEM allowed the real time observation of phenomena occurring near the transformation 
interface during the austenite to ferrite transformation in $\mathrm{Fe}-\mathrm{C}$ alloys and the direct measurement of interface migration rates.

The austenite-ferrite interface moved in different modes. In most cases a segmented interface progressed in a direction perpendicular to the overall interface: the normal mode. The interface velocity was not constant, but showed both accelerations and decelerations different from a jerky motion caused by pinning effects. Frequently a part of the interface adopted a straight configuration which was (almost) immobile. Such an interface could regain mobility by means of ledge movement: the lateral mode. In general, ledge growth was observed in all cases where the progression in the normal mode was hampered.

The maximum migration rates determined for the normal and the lateral mode were compared to values calculated for diffusion controlled growth and for interface controlled growth. The migration rates of the ledges were almost equal to those predicted for diffusion controlled migration. The migration rates for the normal mode varied between almost zero and a maximum value which was somewhat lower compared to the value for diffusion controlled growth.

The interplay between the chemical Gibbs free energy change, driving the transformation, and the opposing strain energy, due to the development of stresses at the interface, may explain the alternating periods of acceleration and deceleration of the interface. Periods of build up of stresses coincided with periods of deceleration of the interface. Periods of dislocation mobility or bending of the foil leading to stress relaxation preceded periods of interface acceleration.

\section{References}

1. J. ÅGREN, Acta Metall. 30 (1982) 841.

2. R. A. VANDERMEER, Acta Metall. Mater. 38 (1990) 2461.

3. M. ENOMOTO, ISIJ Intern. 32 (1992) 297.

4. S. CRUSIUS, L. HÖGLUND, U. KNOOP, G. INDEN and J. ÁGREN, Z. Metallkde 83 (1992) 729.
5. M. ONINK, C. M. BRAKMAN, F. D. TICHELAAR, E. J. MITTEMEIJER, S. VAN DER ZWAAG, J. H. ROOT and N, B. KONYER, Scripta Metall. Mater. 29 (1993) 1011.

6. M. ONINK, F. D. TICHELAAR, C. M. BRAKMAN, E. J. MITTEMEIJER and S. VAN DER ZWAAG, Z. Metallkde accepted.

7. K. SADAMORI, K. ABIKO, H. KIMURA, in "Recrystallisation ' 90 ", edited by T. Chandra, p. 491.

8. D. J. BAR BER and H. R. WENK, Phys. Chem. Minerals 17 (1991) 492.

9. C. LAIRD and H. I. AARONSON, Acta Metall. 17 (1969) 505.

10. A. GARG and J. M. HOWE, Acta Metall. Mater. 39 (1991) 1925.

11. F. KHALID, D. V. EDMONDS, Ibid. 41 (1993) 3421.

12. M. NEMOTO, Metall. Trans. A 8A (1977) 43.

13. G. R. PURDY, Acta Metall. 26 (1978) 477.

14. Idem., ibid. 26 (1978) 487.

15. R. Q. HWAN and R. J. BEHM, J. Vac. Sci. Techn. B 10 (1992) 256.

16. M. O. WATANABE, T. KURODA, K. TANAKA and A. SUCHAI, Ibid. 9 (1991) 924.

17. J. R. BRADLEY, J. M. RIGSBEE and H. I, AARONSON, Metall. Trans. A 8A (1977) 323.

18. K. R. KINSMAN, E. EICHEN and H. I. AARONSON, Ibid. 6A (1975) 303.

19. J. W. CHRISTIAN, "The theory of transformation in metals and alloys, part I," 2nd edition (Pergamon press, Oxford, 1975).

20. V. M. M. SILALAHI, M. ONINK and S. VAN DER ZWAAG, Steel Research in press.

21. D. TURNBULL, Trans AIME 191 (1951) 661.

22. E. A. WIL SON, ISIJ Intern. 34 (1994) 615.

23. G. P. KRIELAART, M. ONINK, F. D. TICHELAAR, C. M. BRAKMAN, E. J. MITTEMEIJER and S. VAN DER ZWAAG, Z, Metallkde 85 (1994) 756.

24. D. R. G. MITCHELL and S. E. DONNELLY, Phil Mag. $A 63$ (1991) 747.

25. H. I. AARONSON, in Symposium on Mechanisms of phase transformation in Metals (Institute of Metals, London, 1955).

26. P. B. HIRSCH, R. B. NICHOLSON, A. HOWIE and D, W. PASHLEY, "Electron Microscopy of Thin Crystals" (Butterworths, London, 1965).

27. J. WEERTMAN, J. WEERTMAN, Elementary dislocation theory" (MacMillan, New York, 1967).

28. O. KUBASCHEWSKI, "Iron binary phase diagrams" (Springer, Berlin, 1982).

Received 22 December 1994

and accepted 2 May 1995 